Al Maal : Journal of Islamic Economics and Banking

http://jurnal.umt.ac.id/index.php/jieb

E-ISSN : $2580-3816$

Vol : 2 No. 1 Bulan Januari Tahun 2021

Hlm : $212-227$

DOI : 10.31000/almaal.v1i2.3741

\title{
Faktor-Faktor Yang Memengaruhi Wakif Dalam Berwakaf Online
}

\author{
Muhammad Izet Budiansyah ${ }^{1}$, Salahuddin El Ayyubi ${ }^{2}$ \\ ${ }^{1,2}$ Departemen Ilmu Ekonomi Syariah, Fakultas Ekonomi dan Manajemen, Institut Pertanian \\ Bogor, Indonesia \\ *izet.budiansyah@gmail.com
}

\section{ABSTRACT}

Waqf is one of Islamic philanthropy that can be an alternative as a welfare distribution and poverty reduction. This instrument has considerable potential in Indonesia. Based on the calculations made by Nasution (2005), cash waqf has a potential reaches to 3 billion Rupiah per year. However, the potential has not been well optimized. Era of digitization provides opportunities for institutions to make online waqf facilities to maximize the potential of cash waqf. This study aims to identify the characteristics of online wakif and the factors affecting wakif in online waqf. A total of 90 respondents of online wakif have been interviewed, with a proportion of 30 wakif coming from three different institutions, including Dompet Dhuafa, Rumah Zakat, and Global Wakaf. The method used to analyze the factors affecting wakif in online waqf is factor analysis. The results of this study showed that the factors affecting wakif in online waqf are five factors, including information quality, service, trust, website quality, and promotion.

Keywords: Cash Waqf; Factor Analysis; Online Waqf.

\begin{abstract}
ABSTRAK
Wakaf merupakan salah satu filantropi Islam yang dapat menjadi alternatif sebagai pemerata kesejahteraan dan pengurang kemiskinan. Instrumen ini memiliki potensi yang cukup besar di Indonesia. Berdasarkan perhitungan yang dilakukan oleh Nasution (2005), wakaf uang memiliki potensi 3 triliun Rupiah per tahun. Namun, angka potensi tersebut belum teroptimalkan dengan baik. Dengan adanya era digitalisasi, beberapa nazhir memberikan fasilitas wakaf online untuk memaksimalkan potensi wakaf uang yang tersedia. Penelitian ini dilakukan dengan tujuan untuk mengidentifikasi karakteristik wakif online serta faktor-faktor yang memengaruhi wakif dalam berwakaf online. Sebanyak 90 responden wakif online telah diteliti, dengan proporsi 30 wakif berasal dari tiga lembaga wakaf yang berbeda diantaranya Dompet Dhuafa, Rumah Zakat, dan Global Wakaf. Metode yang digunakan untuk menganalisis faktor-faktor yang memengaruhi wakif dalam berwakaf online adalah analisis faktor. Hasil penelitian ini menunjukkan bahwa faktor-faktor yang memengaruhi wakif dalam berwakaf online terbagi menjadi lima faktor yaitu faktor kualitas informasi; pelayanan; kepercayaan; kualitas website; dan promosi.
\end{abstract}

Kata kunci : Analisis Faktor; Wakaf Online; Wakaf Uang. 


\section{Pendahuluan}

Pembangunan ekonomi merupakan proses pembangunan yang sedang dihadapi oleh negara berkembang, seperti Indonesia. Upaya pembangunan ekonomi Negara Sedang Berkembang (NSB) dilakukan dengan meningkatkan pendapatan perkapita atau dikenal sebagai strategi pertumbuhan ekonomi (Kuncoro 2010). Namun, upaya yang dilakukan memiliki hubungan yang trade off dengan pemerataan. Artinya, pembangungan yang menitikberatkan pada aspek pertumbuhan cenderung akan mengorbankan aspek pemerataan ekonomi.

Dalam ekonomi Islam, terdapat beberapa instrumen filantropi yang dapat dimanfaatkan sebagai penunjang pembangunan perekonomian, salah satunya adalah wakaf. Menurut Hasanah (2009), wakaf memiliki fungsi sosial sebagai pemerata kesejahteraan dan penanggulangan kemiskinan. Fungsi sosial wakaf akan tercapai apabila pengelolaan wakaf dilakukan secara profesional. Rozalinda (2015) menyatakan bahwa pengelolaan wakaf yang dilakukan secara profesional adalah memberdayakan potensi wakaf secara produktif untuk kepentingan kesejahteraan umat, baik di bidang ekonomi, pendidikan, kesehatan, maupun bidang sosial lainnya.

Berdasarkan data yang terdapat pada Sistem Informasi Wakaf (2016), Indonesia memiliki aset tanah wakaf seluas 435.944,3 hektare. Dari keseluruhan aset tanah wakaf yang tersedia, lebih dari 70 persen pemanfaatannya belum dikelola secara produktif. Aset tanah wakaf yang belum dikelola secara produktif atau menganggur dapat dikembangkan melalui pemanfaatan wakaf uang agar bisa membangun sosial ekonomi masyarakat.

Menurut Nasution (2005), wakaf uang di Indonesia memiliki potensi sebesar 3 triliun Rupiah per tahun. Namun, penelitian yang dilakukan oleh Khadijah (2016) menunjukkan bahwa angka real wakaf uang yang telah dihimpun oleh tujuh lembaga nazhir nasional hanya mencapai 32 miliar rupiah. Tingkat penghimpunan tersebut masih sangat rendah apabila dibandingkan dengan potensi yang ada. Quddus (2009) menyatakan dalam penelitiannya bahwa faktor yang menjadi penghambat terkumpulnya wakaf uang adalah karena masih rendahnya sosialisasi yang dilakukan oleh lembaga penghimpun.

Di sisi lain, dunia teknologi yang semakin berkembang menyebabkan internet menjadi suatu hal yang mudah untuk diakses oleh siapapun. Hal ini membuat manusia memanfaatkan internet untuk segala bidang kehidupan, salah satunya dalam berwakaf. Beberapa lembaga wakaf yang telah memberikan fasilitas berwakaf secara online untuk meningkatkan penghimpunan dana wakaf uang diantaranya adalah Tabung Wakaf (TW), Rumah Wakaf (RW), dan Global Wakaf (GW). Berwakaf secara online merupakan konsepan yang menarik. Selain itu, konsep ini juga memiliki potensi yang cukup besar dalam menghimpun dana wakaf uang.

Bedasarkan penelitian yang dilakukan oleh Fauziah (2018), sebanyak 72 persen dari total respondennya menerima konsep wakaf uang dan berpotensi untuk melakukan wakaf melalui uang. Berwakaf secara online merupakan fasilitas untuk wakif dalam berwakaf uang. Dengan demikian, penelitian ini bertujuan untuk menganalisis karakteristik wakif online dan faktor-faktor yang memengaruhi wakif dalam berwakaf online. 


\section{KAJIAN LITERATUR}

Secara bahasa, wakaf berasal dari bahasa Arab, yaitu dari kata waqafa yang memiliki arti menahan, berhenti, diam di tempat, atau tetap berdiri. Dalam UU No.41 Tahun 2004, wakaf didefinisikan sebagai perbuatan hukum wakif untuk memisahkan dan/atau menyerahkan sebagian harta benda miliknya untuk dimanfaatkan selamanya atau untuk jangka waktu tertentu sesuai dengan kepentingannya guna keperluan ibadah dan/atau kesejahteraan umum menurut syariah. Pasal 6 dalam Undang-Undang Nomor 41 Tahun 2004 disebutkan bahwa wakaf dapat terlaksana dengan memenuhi unsur sebagai berikut:

a. Wakif. Pihak yang melakukan wakaf pada harta benda miliknya. Wakif meliputi wakif perseorangan; organisasi; dan badan hukum yang telah memenuhi ketentuan untuk mewakafkan harta benda wakafnya sesuai dengan anggaran dasar pihak yang bersangkutan.

b. Nazhir. Pihak yang menerima harta benda wakaf dari wakif dan kemudian dikelola serta dikembangkan sesuai dengan peruntukan harta benda wakaf tersebut. Nazhir meliputi perorangan; organisasi; serta badan hukum yang telah memenuhi persyaratan yang ditentukan.

c. Harta benda wakaf. Harta benda yang memiliki daya tahan lama dan/atau manfaat jangka panjang serta mempunyai nilai ekonomi menurut syariah yang diwakafkan oleh wakif. Pada pasal 16 telah dijelaskan secara detail bahwa harta benda wakaf terdiri dari harta benda tidak bergerak dan harta benda bergerak.

d. Ikrar wakaf. Pernyataan kehendak wakif yang diucapkan secara lisan dan/atau tulisan kepada nazhir untuk mewakafkan harta benda miliknya.

e. Peruntukan harta benda wakaf. Keinginan wakif dalam rangka mencapai tujuan dan fungsi benda wakaf. Benda wakaf yang dimanfaatkan sesuai dengan fungsinya merupakan tujuan dari wakaf itu sendiri. Sedangkan perwujudan dari potensi dan manfaat ekonomis harta benda wakaf yang digunakan untuk kepentingan ibadah atau kesejahteraan umat merupakan fungsi wakaf.

f. Jangka waktu wakaf. Batas waktu pemanfaatan harta benda wakaf yang ditentukan oleh wakif. Jangka waktu wakaf bisa bersifat sementara maupun selamanya

Pada pasal 16 telah dijelaskan bahwa uang merupakan salah satu benda bergerak yang termasuk dari harta benda wakaf. Djunaidi (2007) mendefinisikan wakaf uang sebagai wakaf yang dilakukan seseorang, kelompok orang, dan lembaga atau badan hukum dalam bentuk uang. Artinya, wakaf uang merupakan salah satu bentuk wakaf yang diserahkan oleh seorang wakif kepada nazhir dalam bentuk uang kontan (Sudirman dan Arofah 2016). Wakaf tunai sudah dipraktikan sejak awal abad kedua hijriyah. Pada saat itu, Imam alZuhri, salah satu ulama terkemuka, menganjurkan wakaf dinar dan dirham untuk pembangunan sarana sosial, dakwah, dan pendidikan umat Islam.

Wakaf online adalah istilah untuk konsep pengelolaan wakaf melalui basis internet (Tarsi 2014). Ciri yang terdapat pada wakaf online adalah transaksinya yang dilakukan secara online serta pengawasan pengelolaan dan pendistribusian dana wakaf yang dapat diakses melalui website lembaga sebagai pengelola dana wakaf tersebut. Wakaf online dibentuk sebagai fasilitas untuk wakif dalam berwakaf secara efisien. 
Program-program yang terdapat pada wakaf online meliputi dalam bidang ekonomi, pendidikan, kesehatan, dan bidang sosial lainnya. Dalam praktiknya, wakaf online dilaksanakan dalam bentuk benda harta bergerak, yaitu uang. Menurut Antonio (2002), uang sebagai harta benda wakaf memiliki beberapa kelebihan diantaranya:

1. Wakaf uang jumlahnya dapat bervariasi sehingga seseorang dapat berwakaf tanpa harus menjadi hartawan terlebih dahulu.

2. Melalui wakaf uang, aset-aset wakaf tidak produktif, seperti lahan kosong, dapat dimanfaatkan dengan pembangunan gedung atau diolah menjadi lahan pertanian produktif.

3. Dana wakaf uang dapat digunakan untuk membantu lembaga-lembaga pendidikan Islam yang sedang krisis.

4. Dalam jangka waktu beberapa lama, umat Islam akan lebih mandiri dalam mengembangkan dunia pendidikan karena tidak bergantung pada dana anggaran dari Negara yang terbatas.

Layanan berwakaf melalui website adalah penyelenggaraan layanan wakaf untuk menghubungkan wakif kepada proyek wakaf yang sedang dijalani oleh nazhir. Layanan ini mengadopsi sistem crowdfunding. Valanciene dan Jegeleviciute (2014) mengungkapkan bahwa crowdfunding merupakan suatu metode yang bisa menghubungkan para pengusaha yang membutuhkan peningkatan modal dari para investor yang memiliki sumber modal dan ingin berinvestasi melalui entitas intermediari berbasis internet. Vulkan et al. (2016) membagi crowdfunding ke dalam empat kategori, yaitu donasi, pre-selling, lending, equity. Sulaiman (2017) mengatakan bahwa wakaf berbasis crowdfunding memiliki potensi yang besar sebagai mekanisme pengumpul dana untuk para pengusaha muslim yang sesuai dengan prinsip syariah.

Yuniarty dan Abbas (2018) melakukan penelitian tentang Faktor-Faktor Penentu Keputusan Pembelian Melalui E-commerce pada PT. GRE. Penelitian ini menyatakan bahwa variabel independen yang berpengaruh signifikan secara simultan terhadap variabel dependennya meliputi variabel kualitas informasi, reputasi perusahaan, dihasilkan nilai adjusted $\mathrm{r}$ square sebesar 0,663. Artinya adalah variasi pada variable independen yang digunakan dalam model regresi mampu menjelaskan sebesar 66,3 persen pada variabel dependennya.

Syarif dan Wijayanto (2017) melakukan penelitian tentang Analisis Pengaruh Kemenarikan Desain Website, Kepercayaan dan Profesionalisme terhadap Keputusan Pembelian Online Jasa Aqiqah. Penelitian ini menyatakan bahwa variabel kemenarikan desain website dan kepercayaan berpengaruh signifikan positif terhadap variabel keputusan pembelian dan memiliki nilai adjusted $r$ square sebesar 0,465. Artinya adalah variasi pada variable independen yang digunakan dalam model regresi mampu menjelaskan sebesar 46,5 persen pada variabel dependennya.

Penelitian yang dilakukan oleh Mauludiyahwati (2017) bertujuan untuk mengetahui pengaruh kepercayaan, keamanan, kualitas pelayanan, dan persepsi risiko baik secara parsial maupun simultan terhadap keputusan pembelian online pada situs lazada.co.id. Hasil penelitian menunjukkan bahwa kepercayaan, keamanan, kualitas pelayanan, dan persepsi risiko memiliki pengaruh signifikan positif terhadap keputusan pembelian online di situs lazada.co.id 


\section{Metode Penelitian}

Penelitian ini dilakukan pada tiga lembaga wakaf, yaitu Tabung Wakaf (TW), Rumah Wakaf (RW), dan Global Wakaf (GW). Lokasi penelitian dipilih secara sengaja dengan pertimbangan bahwa TW, RW, dan GW merupakan tiga lembaga wakaf berskala nasional yang telah memanfaatkan situs website untuk menghimpun dana wakaf.

Data yang digunakan pada penelitian ini meliputi data primer dan data sekunder. Data primer diperoleh dari penyebaran kuesioner secara online pada pengikut akun instagram Dompet Dhuafa, Rumah Zakat, dan Global Wakaf. Pengambilan data dimulai dari April - Mei 2019. Sedangkan data sekunder diperoleh melalui kajian pustaka dari berbagai sumber literatur yang relevan dengan topik penelitian sejenis, seperti skripsi, tesis, jurnal, website lembaga terkait, dan Sistem Informasi Wakaf (SIWAK).

Dalam penarikan sampel, penelitian ini menggunakan non-probability sampling dengan teknik purposive sampling. Populasi yang digunakan pada penelitian ini adalah masyarakat Indonesia yang telah berwakaf secara online melalui situs website pada lembaga Tabung Wakaf, Rumah Wakaf dan Global Wakaf. Sampel yang digunakan pada penelitian adalah sebanyak 90 orang yang terdiri atas:

1) Sebanyak 30 responden wakif yang berwakaf pada lembaga Tabung Wakaf.

2) Sebanyak 30 responden wakif yang berwakaf pada lembaga Rumah Wakaf.

3) Sebanyak 30 responden wakif yang berwakaf pada lembaga Global Wakaf.

Besarnya ukuran sampel ditetapkan berdasarkan Roscoe dalam Supriyadi (2014) yang menyatakan bahwa secara umum dalam penelitian analisis faktor, jumlah sampel yang digunakan berjumlah 50 sampai 100 sampel atau responden.

Tabel 1. Variabel Penelitian

\begin{tabular}{ll}
\hline \multicolumn{1}{c}{ Variabel } & \multicolumn{1}{c}{ Nama Variabel } \\
\hline var1 & Penyaluran dana wakaf jelas \\
var2 & Reputasi lembaga baik \\
var3 & Lembaga wakaf bertanggung jawab \\
var4 & Lembaga wakaf menjaga informasi pribadi \\
var5 & Website mudah diakses \\
var6 & Sistem kerja website mudah \\
var7 & Adanya konfirmasi setelah bertransaksi \\
var8 & Customer service yang sigap \\
var9 & Adanya kaporan rutin \\
var10 & Customer service yang sopan \\
var11 & Fasilitas situs yang lengkap \\
var12 & Adanya tutorial video wakaf online \\
var13 & Penawaran berwakaf dari orang lembaga \\
var14 & Informasi tata cara bertransaksi \\
var15 & Informasi kontak jelas \\
var16 & Informasi program wakaf \\
var17 & Informasi penghimpunan dana wakaf
\end{tabular}




$\begin{array}{ll}\text { var18 } & \text { Gaya tulisan mudah dibaca } \\ \text { var19 } & \text { Kombinasi warna situs menarik }\end{array}$

Penelitian ini menggunakan dua metode analisis data, yaitu analisis deskriptif dan analisis faktor. Analisis deskriptif adalah metode yang digunakan untuk mengidentifikasi karakteristik responden. Data yang diperoleh melalui penyebaran kuesioner dikelompokkan pada gambar/tabel dan dipersentasekan berdasarkan jumlah responden. Analisis faktor merupakan teknik analisis interdependensi yang digunakan untuk mengelompokkan banyak variabel menjadi variabel laten/faktor yang lebih sedikit daripada variabel yang diteliti (Suliyanto 2005). Prinsip pada analisis faktor digunakan untuk mengelompokkan beberapa variabel yang memiliki kemiripan untuk dijadikan satu faktor, sehingga dimungkinkan dari beberapa atribut yang memengaruhi suatu komponen variabel dapat diringkas menjadi beberapa faktor utama yang jumlahnya lebih sedikit. Berikut beberapa asumsi-asumsi yang terdapat pada analisis faktor (Suliyanto 2005):

1. Uji Determinant of Correlation Matrix. Uji yang digunakan untuk melihat korelasi atau keterkaitan antarvariabel. Dalam analisis faktor, setiap variabel yang digunakan harus memiliki korelasi yang kuat antar semua variabel. Antar variabel dikatakan saling mengikat apabila nilai Determinant of Correlation Matrix pada output Matrix Correlation adalah 0 atau mendekati 0.

2. Uji Kaiser Meyer Olkin Measure of Sampling KMO merupakan sebuah indeks perbandingan jarak antar koefisien korelasi dengan koefisien korelasi parsialnya. Jika jumlah kuadrat koefisien korelasi parsial di antara seluruh pasangan variabel bernilai kecil dibandingkan dengan jumlah kuadrat koefisien korelasi, maka akan menghasilkan nilai KMO yang mendekati satu. Nilai KMO yang kecil menunjukkan bahwa analisis faktor bukan merupakan pilihan yang tepat. Untuk dapat dilakukan analisis faktor, nilai KMO dianggap cukup apabila $\geq 0.5$.

3. Nilai Measure of Sampling Adequacy. MSA merupakan sebuah indeks perbandingan jarak antara koefisien korelasi dengan koefisien korelasi parsialnya. Untuk dapat dilakukan analisis faktor, nilai MSA pada setiap variabel harus $\geq 0.5$. Apabila ada item/variabel yang tidak memiliki nilai MSA $\geq 0.5$, variabel tersebut harus dikeluarkan dari analisis faktor secara bertahap (dimulai dari angka MSA terkecil).

\section{HASIL DAN PEMBAHASAN \\ Karakteristik Wakif yang Berwakaf Online}

Karakteristik umum responden merupakan hasil dari pengisian kuesioner secara online yang disebar melalui link google kepada pengikut akun instagram dari Dompet Dhuafa, Rumah Zakat, dan Global Wakaf. Responden dalam penelitian ini adalah orang yang pernah melakukan wakaf tunai secara online, baik melalui Dompet Dhuafa, Rumah Zakat, maupun Global Wakaf. Karakteristik wakif yang akan dijelaskan dalam penelitian ini antara lain, jenis kelamin, usia, pendidikan terakhir, dan penghasilan. 
Tabel 2. Karakteristik Wakif Online berdasarkan Jenis Kelamin

\begin{tabular}{llll}
\hline & Karakteristik & Jumlah & \multicolumn{1}{c}{ Persentase (\%) } \\
\hline \multirow{2}{*}{ Jenis Kelamin } & Laki-Laki & 42 & $46,67 \%$ \\
Total & Perempuan & 48 & $53,33 \%$ \\
& & 90 & $100,00 \%$ \\
\hline
\end{tabular}

Sumber: diolah oleh penulis

Terlihat dalam Tabel 2, karakteristik jenis kelamin wakif yang mendominasi adalah perempuan, yaitu sebanyak 53,33 persen. Responden perempuan lebih mendominasi dalam penelitian ini menunjukkan bahwa perempuan dinilai lebih bersifat religius daripada laki-laki. Berdasarkan penelitian yang dilakukan oleh PEW Research dengan judul "U.S Religious Landscape" pada 2014 menyatakan bahwa sebanyak 59 persen perempuan menganggap agama merupakan suatu hal yang sangat penting untuk kehidupan mereka, sedangkan untuk pria hanya mencapai 47 persen dari populasi yang diteliti. Berwakaf merupakan kegiatan yang masih identik dengan tingkat religiusitas seseorang. Artinya, semakin religius seseorang, orang tersebut akan memiliki keinginan yang kuat untuk berwakaf. Hasil ini diperkuat dengan penelitian yang dilakukan oleh Fauziah (2017) serta penelitian yang dilakukan Sari (2018) yang menyatakan bahwa religiusitas berpengaruh signifikan positif terhadap keputusan berwakaf.

Tabel 3. Karakteristik Wakif Online berdasarkan Tingkat Usia

\begin{tabular}{|c|c|c|c|}
\hline & Karakteristik & Jumlah & Persentase (\%) \\
\hline & $<19$ tahun & 2 & $2,22 \%$ \\
\hline Usia & $19-34$ tahun & 85 & $94,44 \%$ \\
\hline & $35-55$ tahun & 3 & $3,33 \%$ \\
\hline Total & & 90 & $100.00 \%$ \\
\hline
\end{tabular}

Sumber:diolah oleh penulis

Berdasarkan tabel 3, sebanyak 94,44 persen responden berada di rentang usia 1934 tahun. Menurut Bencsik et al. (2016) dalam penelitiannya yang berjudul $Y$ and $Z$ Generations at Workplace menjelaskan bahwa usia pada 19-34 tahun termasuk dalam Generasi Y dan Generasi Z. Generasi Y merupakan generasi yang tumbuh pada era internet booming (Lyons 2004). Generasi ini didominasi oleh pengguna teknologi komunikasi instan, seperti email dan media sosial, seperti facebook. Sedangkan Generasi $\mathrm{Z}$ memiliki definisi dan kemiripan yang sama dengan Generasi Y. Namun, Generasi Z lebih bersifat multi tasking, mampu mengaplikasikan semuanya dalam satu waktu. Selain itu, survei yang dilakukan oleh APJII pada tahun 2017 juga menyatakan bahwa pengguna internet di Indonesia didominasi pada rentang usia 19 sampai 34 tahun sebanyak 49,52 persen, sehingga rentang usia tersebut mendominasi wakif yang berwakaf secara online.

Tabel 4. Karakteristik Wakif Online berdasarkan Pendidikan Terakhir

\begin{tabular}{llll}
\hline & \multicolumn{1}{c}{ Karakteristik } & Jumlah & \multicolumn{1}{c}{ Persentase (\%) } \\
\hline \multirow{3}{*}{ Pendidikan Terakhir } & SMA & 29 & $32,22 \%$ \\
& D3/S1 & 56 & $62,22 \%$ \\
Total & S2/S3 & 5 & $5,56 \%$ \\
\hline
\end{tabular}


Berdasarkan tingkat pendidikan terakhir, responden wakif online didominasi oleh lulusan D3/S1 sebesar 60,22 persen dan S2/S3 sebesar 5,56 persen. Sisanya, 32,22 persen merupakan responden yang berpendidikan terakhir lulusan SMA dengan sebesar 58,62 persen merupakan responden yang sedang menempuh pendidikan di perguruan tinggi (mahasiswa). Artinya, responden wakif online pada penelitian ini didominasi oleh orang yang berpendidikan tinggi sehingga pengetahuan mereka terhadap sesuatu semakin baik. Berdasarkan penelitian yang dilakukan oleh Nizar (2014), dilihat dari tingkat pendidikan, sebesar 82 persen responden pada penelitiannya menerima wakaf uang. Persentase tersebut didominasi oleh orang yang berpendidikan tinggi, yaitu sebesar 64 persen responden. Hasil penelitiannya menyatakan bahwa kemungkinan responden untuk menerima wakaf uang dibandingkan menolak wakaf uang untuk kelompok berpendidikan tinggi lebih tinggi sebesar 36 kali dibandingkan kelompok berpendidikan rendah.

Tabel 5. Karakteristik Wakif Online berdasarkan Penghasilan

\begin{tabular}{llll}
\hline & \multicolumn{1}{c}{ Karakteristik } & Jumlah & \multicolumn{1}{c}{ Persentase (\%) } \\
\hline \multirow{4}{*}{ Penghasilan } & $<$ Rp500.000 & 12 & $13,33 \%$ \\
& Rp500.000-Rp 1.999.999 & 23 & $25,26 \%$ \\
& Rp2.000.000-Rp4.999.999 & 32 & $35,56 \%$ \\
& Rp5.000.000-Rp9.999.999 & 16 & $17,78 \%$ \\
& $>$ Rp10.000.000 & 7 & $7,78 \%$ \\
& & 90 & $100.00 \%$ \\
\hline
\end{tabular}

Sumber: diolah oleh penulis

Berdasarkan tingkat penghasilan, responden yang berwakaf online didominasi oleh penghasilan rendah, < Rp2.000.000/bulan, yaitu sebesar 38,59 persen. Hal ini disebabkan karena 28,89 persen responden dalam penelitian ini berprofesi sebagai mahasiswa yang identik belum bekerja formal. Kemudian, sebanyak 35,56 persen responden berpenghasilan menengah, Rp2.000.000/bulan sampai Rp4.999.999/bulan, dan sisanya, 25,56 persen, merupakan responden dengan penghasilan $\geq$ Rp5.000.000/bulan. Hasil ini sesuai dengan penelitian yang dilakukan oleh Kasri (2013) yang menyatakan bahwa pendapatan tinggi seseorang tidak menjamin orang tersebut untuk memberikan donasi pada badan amal.

\section{Faktor-Faktor yang Memengaruhi Wakif dalam Berwakaf Online} Uji Asumsi Model Analisis Faktor

Asumsi pertama yang harus dipenuhi dalam analisis faktor adalah uji Determinant Correlation of Matrix yang digunakan untuk melihat korelasi antar variabel saling terikat. Berdasarkan hasil analisis, nilai Determinant of Correlation Matrix sebesar 0, sehingga korelasi antar variabel dapat dikatakan saling terikat.

Asumsi kedua adalah uji KMO and Bartlett's Test. Suatu kumpulan variabel dinyatakan layak untuk dianalisis menggunakan analisis faktor apabila nilai KMO berada di atas 0,5 dengan hasil Batrlett's Test of Spheracity signifikan, yaitu $<0.5$. 
Tabel 6. Hasil Uji KMO

\begin{tabular}{|c|c|c|}
\hline \multicolumn{3}{|c|}{ KMO and Bartlett's Test } \\
\hline \multicolumn{2}{|c|}{ Kaiser-Meyer-Olkin Measure of Sampling Adequacy } & 0,795 \\
\hline \multirow[t]{3}{*}{ Bartlett's Test of Sphericity } & Approx Chi-Square & 750,564 \\
\hline & $D f$ & 213 \\
\hline & Sig &, 000 \\
\hline
\end{tabular}

Sumber: data primer, diolah oleh penulis

Berdasarkan Tabel 6, nilai KMO and Bartlett's Test terlihat dengan angka K-M-O Measure of Sampling Adequacy (MSA) adalah 0,795. Oleh karena angka MSA di atas 0,5 , maka kumpulan variabel tersebut dapat diproses lebih lanjut. Kesimpulan yang sama dapat dilihat pada angka Bartlett's Test of Sphericity dengan angka Chi-Square sebesar 750,564 dengan signifikansi ,000.

Asumsi ketiga adalah melihat nilai MSA yang terdapat pada output Anti-image Matrices di bagian Anti-image Correlation. Tahapan ini dilakukan untuk mengetahui variabel mana yang dapat diproses lebih lanjut dan mana yang harus dikeluarkan. Suatu variabel dapat dianalisis lebih lanjut apabila nilai MSA berada di atas 0,5. Berdasarkan hasil analisis, semua variabel memiliki nilai MSA > 0,5. Artinya, semua variabel layak untuk dianalisis lebih lanjut.

\section{Analisis Faktor}

Setelah setiap asumsi terpenuhi, hal selanjutnya yang dilakukan adalah melihat nilai extraction yang terdapat pada tabel Communalities. Tabel Communalities berfungsi sebagai penjelas faktor dari variabel yang diteliti. Variabel dapat dikatakan mampu menjelaskan faktor yang terbentuk apabila nilai extraction $>0.5$.

Tabel 7. Hasil Communalities

\begin{tabular}{lll}
\hline \multicolumn{1}{c}{ Variabel } & Initial & Extraction \\
\hline Var1 & 1,000 & 0,581 \\
Var2 & 1,000 & 0,629 \\
Var3 & 1,000 & 0,756 \\
Var4 & 1,000 & 0,794 \\
Var5 & 1,000 & 0,591 \\
Var6 & 1,000 & 0,530 \\
Var7 & 1,000 & 0,643 \\
Var8 & 1,000 & 0,610 \\
Var9 & 1,000 & 0,692 \\
Var10 & 1,000 & 0,633 \\
Var11 & 1,000 & 0,589 \\
Var12 & 1,000 & 0,644 \\
Var13 & 1,000 & 0,685 \\
Var14 & 1,000 & 0,620 \\
Var15 & 1,000 & 0,671 \\
Var16 & 1,000 & 0,816 \\
Var17 & 1,000 & 0,556 \\
Var18 & 1,000 & 0,683
\end{tabular}




$\begin{array}{cc}\text { Var19 } \quad 1,000 & 0,735 \\ \text { Sumber: data primer, diolah oleh penulis }\end{array}$

Berdasarkan Tabel 7, nilai ekstraksi paling tinggi adalah var16 (0.816). Interpretasi dari nilai tersebut adalah sebesar 81.6 persen varians dari var16, informasi program wakaf, dapat menjelaskan faktor yang terbentuk. Sedangkan nilai ekstraksi paling rendah adalah var6 (0.530). Interpretasi dari nilai tersebut adalah sebesar 53 persen varians dari var6, sistem kerja website mudah, dapat menjelaskan faktor yang terbentuk. Begitu juga dengan 17 variabel lainnya, semakin tinggi nilai ekstraksi, semakin kuat hubungan variabel dengan faktor.

Tahap berikutnya adalah melihat Total Variance Explained (Gambar 1) untuk menentukan jumlah faktor yang terbentuk. Apabila Total Initial Eigenvalues $>1$, maka faktor tersebut dapat menjelaskan indikator dengan baik sehingga perlu disetarakan.

\section{Gambar 1. Total Variance Explained}

\begin{tabular}{|c|c|c|c|c|c|c|c|c|c|}
\hline \multicolumn{10}{|c|}{ Total Variance Explained } \\
\hline \multirow[b]{2}{*}{ Component } & \multicolumn{3}{|c|}{ Initial Eigenvalues } & \multicolumn{3}{|c|}{ Extraction Sums of Squared Loadings } & \multicolumn{3}{|c|}{ Rotation Sums of Squared Loadings } \\
\hline & Total & $\%$ of Variance & Cumulative \% & Total & $\%$ of Variance & Cumulative \% & Total & $\%$ of Variance $\mathrm{C}$ & Cumulative \% \\
\hline 1 & 6,556 & 34,508 & 34,508 & 6,556 & 34,508 & 34,508 & 3,008 & 15,830 & 15,830 \\
\hline 2 & 1,756 & 9,243 & 43,751 & 1,756 & 9,243 & 43,751 & 2,878 & 15,149 & 30,979 \\
\hline 3 & 1,547 & 8,141 & 51,892 & 1,547 & 8,141 & 51,892 & 2,688 & 14,149 & 45,128 \\
\hline 4 & 1,420 & 7,473 & 59,365 & 1,420 & 7,473 & 59,365 & 2,189 & 11,522 & 56,650 \\
\hline 5 & 1,180 & 6,212 & 65,577 & 1,180 & 6,212 & 65,577 & 1,696 & 8,927 & 65,577 \\
\hline 6 & 0,886 & 4,665 & 70,242 & & & & & & \\
\hline 7 & 0,753 & 3,963 & 74,205 & & & & & & \\
\hline 8 & 0,730 & 3,842 & 78,047 & & & & & & \\
\hline 9 & 0,660 & 3,475 & 81,522 & & & & & & \\
\hline 10 & 0,580 & 3,054 & 84,576 & & & & & & \\
\hline 11 & 0,538 & 2,830 & 87,406 & & & & & & \\
\hline 12 & 0,506 & 2,661 & 90,067 & & & & & & \\
\hline 13 & 0,423 & 2,224 & 92,291 & & & & & & \\
\hline 14 & 0,338 & 1,780 & 94,071 & & & & & & \\
\hline 15 & 0,295 & 1,553 & 95,624 & & & & & & \\
\hline 16 & 0,276 & 1,453 & 97,077 & & & & & & \\
\hline 17 & 0,233 & 1,229 & 98,306 & & & & & & \\
\hline 18 & 0,187 & 0,983 & 99,288 & & & & & & \\
\hline 19 & 0,135 & 0,712 & 100,000 & & & & & & \\
\hline
\end{tabular}

Sumber: diolah oleh penulis

Berdasarkan Gambar 1, terdapat 5 faktor atau component yang memiliki nilai Total Initial Eigenvalues > 1, dengan masing-masing faktor bernilai 6,556; 1,756; 1,547; 1,420; dan 1,180. Kelima komponen tersebut memiliki total varians sebesar 65,577 persen. Artinya, lima faktor yang terbentuk menurut pandangan responden dalam penelitian ini dapat memengaruhi wakif dalam berwakaf online sebesar 65,577 persen dan sisanya dapat dijelaskan oleh faktor lain di luar model penelitian (Widarjono 2015).

Setelah faktor terbentuk yang didasari dari nilai Total Initial Eigenvalues $>1$, selanjutnya adalah mengklasifikasikan variabel-variabel penelitian ke dalam masingmasing faktor. Pengklasifikasian variabel ke dalam faktor didasarkan dari nilai factor loading yang terdapat pada tabel Rotated Component Matrix hasil rotasi dengan metode varimax. Semakin besar nilai factor loading pada komponen tertentu artinya variabel tersebut memiliki pengaruh yang nyata di komponen tersebut. 
Tabel 8. Rotated Component Matrix

\begin{tabular}{llllll}
\hline \multicolumn{5}{c}{} & \multicolumn{5}{c}{ Component } \\
& 1 & 2 & 3 & 4 & 5 \\
\hline var1 & 0,267 & 0,133 & 0,626 & 0,008 & 0,316 \\
var2 & 0,120 & 0,223 & 0,631 & 0,363 & 0,186 \\
var3 & 0,158 & 0,069 & 0,838 & 0,155 & 0,022 \\
var4 & 0,138 & 0,187 & 0,838 & 0,133 & 0,140 \\
var5 & 0,121 & 0,383 & 0,353 & 0,475 & 0,284 \\
var6 & 0,248 & 0,198 & 0,319 & 0,571 & 0,044 \\
var7 & 0,005 & 0,768 & 0,118 & 0,193 & 0,040 \\
var8 & 0,116 & 0,724 & 0,170 & 0,108 & 0,177 \\
var9 & 0,303 & 0,623 & 0,154 & 0,156 & 0,406 \\
var10 & 0,243 & 0,710 & 0,112 & 0,155 & 0,182 \\
var11 & 0,407 & 0,556 & 0,149 & 0,270 & 0,140 \\
var12 & 0,156 & 0,377 & 0,086 & 0,209 & 0,653 \\
var13 & 0,075 & 0,050 & 0,158 & 0,172 & 0,789 \\
var14 & 0,710 & 0,065 & 0,203 & 0,263 & 0,048 \\
var15 & 0,780 & 0,205 & 0,126 & 0,055 & 0,041 \\
var16 & $\mathbf{0 , 8 4 9}$ & 0,160 & 0,208 & 0,118 & 0,112 \\
var17 & $\mathbf{0 , 6 8 5}$ & 0,124 & 0,081 & 0,197 & 0,163 \\
var18 & 0,374 & 0,167 & 0,067 & $\mathbf{0 , 6 9 0}$ & 0,186 \\
var19 & 0,004 & 0,097 & 0,154 & $\mathbf{0 , 7 8 7}$ & 0,286 \\
\hline
\end{tabular}

Sumber: data primer, diolah oleh penulis

Terlihat dalam Tabel 8, bahwa korelasi var1 (penyaluran dana wakaf jelas) dengan faktor $1,2,3,4$, dan 5 sebesar $0.267 ; 0.133 ; 0.626$; 0.008; 0.316. Nilai korelasi var1 dengan faktor 3 merupakan yang tertinggi. Dengan demikian, var1 merupakan bagian dari faktor 3. Begitu juga dengan variabel-variabel lainnya. Suatu variabel dapat dikatakan tidak memiliki kontribusi pada faktor apabila nilai factor loading yang dimiliki $<0.55$. Pada Tabel 9 dapat dilihat pengelompokkan variabel dalam 5 faktor hasil reduksi yang sudah diberi nama 26 berdasarkan nilai factor loading tertinggi. Pengelompokkan (Tabel 8) dirangkum dari hasil olahan matriks dengan metode varimax yang menampilkan nilai factor loading > 0.55 (Santoso 2014).

Tabel 9. Faktor-Faktor yang Memengaruhi Wakif dalam Berwakaf Online

\begin{tabular}{llc}
\hline \multicolumn{1}{c}{ Factor } & $\begin{array}{c}\text { Factor } \\
\text { loading }\end{array}$ & \% of Cumulative \\
\hline Faktor Kualitas Informasi & & 15,830 \\
(var16) Informasi program wakaf & 0,849 & \\
(var15) Informasi kontak jelas & 0,780 & \\
(var14) Informasi tata cara bertransaksi & 0,710 & \\
(var17) Informasi penghimpunan dana wakaf & 0,685 & 15,149 \\
Faktor Pelayanan & & \\
(var7) Adanya konfirmasi setelah bertransaksi & 0,768 &
\end{tabular}




$\begin{array}{lll}\text { (var8) Customer service yang sigap } & 0,724 & \\ \text { (var10) Customer service yang sopan } & 0,710 & \\ \text { (var9) Adanya laporan rutin } & 0,623 & 14,149 \\ \text { (var11) Fasilitas situs yang lengkap } & 0,556 & \\ \text { Faktor Kepercayaan } & & \\ \text { (var3) Lembaga wakaf bertanggung jawab } & 0,838 & \\ \text { (var4) Lembaga wakaf menjaga informasi pribadi } & 0,838 & \\ \text { (var2) Reputasi lembaga baik } & 0,631 & \\ \text { (var1) Penyaluran dana wakaf jelas } & 0,626 & \\ \text { Faktor Kualitas Website } & & \\ \text { (var19) Kombinasi warna situs menarik } & 0,787 & \\ \text { (var18) Gaya tulisan mudah dibaca } & 0,690 \\ \text { (var6) Sistem kerja website mudah } & 0,571 & \\ \text { Faktor Promosi } & & \\ \text { (var13) Penawaran berwakaf dari orang lembaga } & 0,789 & \\ \text { (var12) Adanya tutorial video wakaf online } & \text { Sumber: data primer, diolah oleh penulis }\end{array}$

\section{Faktor Kualitas Informasi}

Faktor yang pertama yaitu faktor kualitas informasi. Faktor ini memiliki nilai varians 15,830 persen atau yang terbesar dibandingkan faktor lainnya, sehingga dapat disimpulkan bahwa faktor ini merupakan faktor yang paling dominan yang memengaruhi wakif dalam berwakaf online. Faktor ini terdiri dari 4 variabel, yaitu var16 (Informasi program wakaf), var15 (Informasi kontak jelas), var14 (Informasi tata cara bertransaksi), dan var17 (Informasi penghimpunan dana wakaf). Pada faktor ini, variabel yang mendapatkan nilai tertinggi adalah var16 dengan nilai factor loading sebesar 0,849 . Artinya, informasi program wakaf memberikan kontribusi terbesar bagi wakif untuk berwakaf online. Adanya informasi ini memberikan kepastian kepada wakif terkait wakaf uang yang mereka salurkan akan dialokasikan sesuai dengan tujuan dan fungsi wakaf. Selanjutnya, var15 yaitu informasi kontak jelas memiliki nilai factor loading tertinggi kedua sebesar 0,780. Artinya, website yang mencatumkan berbagai informasi kontak, seperti alamat kantor, no.telp lembaga, email, serta call center, akan membuat wakif semakin percaya terhadap website lembaga tersebut. Var14, informasi tata cara bertransaksi, memiliki nilai factor loading tertinggi ketiga, yaitu 0,710. Informasi tata cara bertransaksi akan memberikan kemudahan bagi para wakif yang ingin melaksanakan wakaf online di lembaga tersebut. Hal ini akan sangat bermanfaat bagi donatur baru terutama untuk mereka yang sebelumnya tidak pernah melaksanakan transaksi secara online. Informasi mengenai penghimpunan dana wakaf memiliki nilai factor loading sebesar 0,685. Informasi ini ditujukan sebagai salah satu bentuk transparansi dari pihak lembaga atas dana yang sudah mereka kumpulkan. Transparansi merupakan hal yang sebaiknya dilakukan untuk setiap lembaga sosial yang mengelola dana publik. Hal ini dilakukan untuk meningkatkan kredibilitas sebuah lembaga.

\section{Faktor Pelayanan}

Faktor kedua yang terbentuk dari proses analisis faktor pada penelitian ini yaitu faktor pelayanan yang terdiri dari var8 (customer service yang sigap), var7 (adanya 
konfirmasi setelah bertransaksi), var10 (customer service yang sopan), var11 (fasilitas situs website yang lengkap), dan var9 (adanya laporan rutin). Faktor ini memiliki nilai varians sebesar 15,149 persen. Var9, adanya konfirmasi setelah bertransaksi, merupakan variabel yang memiliki nilai factor loading tertinggi pada faktor ini, yaitu 0,768 . Konfirmasi penerimaan dana yang dikirim oleh lembaga kepada donatur, baik melalui email maupun nomor telepon, merupakan suatu hal yang harus dilakukan oleh lembaga. Selain sebagai bentuk keandalan lembaga, konfirmasi ini akan memberikan kepastian kepada donatur bahwa dana yang telah mereka kirim telah diterima oleh lembaga tersebut. Selanjutnya var10, customer service yang sigap, yang memiliki nilai factor loading sebesar 0,724. Customer service atau dalam hal lain juga sebagai admin pada media sosial harus selalu sigap dalam memberikan tanggapan kepada para wakif atau calon wakif. Hal ini merupakan sebagai bentuk daya tanggap (responsiveness) suatu lembaga dalam memberikan pelayanan kepada pelanggan mereka sehingga bisa menarik konsumen dan memberikan kepuasan. Kemudian var10, customer service yang sopan, merupakan variabel yang memiliki nilai factor loading tertinggi ketiga, yaitu sebesar 0,694. Pelayanan dalam hal ini adalah memberikan tanggapan berupa balasan chatting yang dikirimkan oleh donatur ataupun calon donatur. Pelayanan ini juga sebagai bentuk empathy lembaga kepada konsumen. Selanjutnya adalah var9, adanya laporan rutin, memiliki nilai factor loading sebesar 0,623. Laporan rutin yang diberikan lembaga kepada donatur melalui akun pribadi merupakan salah satu bentuk transparansi dari lembaga. Tujuannya adalah untuk menyampaikan informasi kepada donatur bahwa dana yang mereka berikan telah disalurkan sesuai dengan tujuan dan fungsi wakaf. Var11, fasilitas situs website yang lengkap, memiliki nilai factor loading terendah pada faktor ini, yaitu sebesar 0,556. Hal ini merupakan bentuk nyata (tangible) dari lembaga website. Menurut penelitian Wijaya et al (2012), ada 8 sub-komponen dari fitur ecommerce, yaitu prospective customer info need; current customer info need; company introducing info; company knowledge products; information regarding 28 to products \& services; information regarding to marketing sales \& support; personal info; historical info. Wakaf online memiliki kemiripan dengan belanja online. Oleh karena itu, fitur-fitur yang sekiranya ada di website toko online bisa diterapkan juga terhadap website pada lembaga wakaf

\section{Faktor Kepercayaan}

Faktor selanjutnya yaitu faktor yang ketiga yang dinamakan dengan faktor kepercayaan. Faktor ini meliputi var3 (lembaga wakaf bertanggung jawab), var4 (lembaga wakaf menjaga informasi pribadi), var1 (penyaluran dana wakaf jelas), dan var3 (reputasi lembaga baik). Faktor kepercayaan memiliki nilai variansi sebesar 14,149 persen. Variabel yang paling memengaruhi faktor ini adalah var3, lembaga wakaf bertanggung jawab, dengan nilai factor loading 0,838. Tanggung jawab yang harus dilakukan oleh lembaga wakaf online meliputi dua hal, yaitu tanggung jawabnya sebagai nazhir serta tanggung jawabnya sebagai lembaga penghimpun dana secara online. Tanggung jawab nazhir sudah tercantum dalam Pasal 11 UU No.41 Tahun 2004 dan tanggung jawab sebagai penghimpun dana secara online seperti menjaga informasi pribadi para donatur yang menjadi var4 dalam penelitian ini. Var4 memiliki nilai factor loading sebesar 0,838. Variabel ini merupakan variabel tertinggi ketiga yang paling memengaruhi wakif dalam berwakaf online, setelah var16 dan var3. Selanjutnya adalah var2, reputasi lembaga baik, dengan nilai factor loading sebesar 0,631. Reputasi merupakan suatu gambaran yang ada di benak seseorang. Reputasi bisa menjadi baik atau 
buruk tergantung dari kemampuan dan keadaan yang sebenarnya dari lembaga tersebut. Semakin baik reputasi website pada lembaga, maka donatur akan semakin mempercayai dana mereka untuk dikelola melalui lembaga tersebut.

\section{Faktor Kualitas Website}

Faktor selanjutnya adalah faktor kualitas website yang terdiri dari tiga variabel, yaitu var19 (kombinasi warna situs menarik); var18 (gaya tulisan yang mudah dibaca); dan var6 (sistem kerja website mudah). Faktor ini memiliki nilai varians 11,522 persen. Variabel yang pertama adalah var19, kombinasi warna situs menarik, dengan nilai factor loading sebesar 0,787. Permainan warna pada halaman situs dapat memberi kesan bahwa pengelola situs lembaga terlihat profesional. Selain itu, kombinasi warna yang menarik juga membuat pandangan pengunjung situs menjadi lebih nyaman. Selanjutnya adalah var18, gaya tulisan yang mudah dibaca, dengan nilai factor loading sebesar 0,690. Sama halnya dengan permainan warna pada halaman, penggunaan font tulisan juga dapat memberikan kesan yang profesional terhadap lembaga situs tersebut. Variabel ketiga pada faktor ini yaitu var6, sistem kerja website mudah, dengan factor loading sebesar 0,571 . Sistem kerja yang mudah dirasa membuat website menjadi user friendly karena dengan nyamannya donatur atau calon donatur menjelajah website lembaga dan dengan mudah mengunggah daya tarik pengunjung.

\section{Faktor Promosi}

Faktor terakhir yang terbentuk dalam penelitian ini adalah faktor promosi yang terdiri dari dua variabel, yaitu var13 (penawaran berwakaf dari orang lembaga) dan var12 (adanya tutorial video wakaf online) dengan nilai varians 8,927 persen. Variabel pertama adalah var13 yang memiliki nilai factor loading sebesar 0,789. Dalam teknik pemasaran, var13 termasuk dalam jenis personal selling, atau penjualan tatap muka. Pada penelitian yang dilakukan oleh Fauzi (2009), kegiatan personal selling dapat memengaruhi keputusan pembelian sebesar 51,48 persen. Selanjutnya adalah var12 yang memiliki nilai factor loading sebesar 0,653. Tujuan dari variabel ini adalah untuk menginformasikan tata cara 30 berwakaf di lembaga situs tersebut dalam bentuk video. Promosi melalui video dirasa lebih efektif karena mudah untuk membaginya ke berbagai khalayak dan ke berbagai media, seperti media sosial.

\section{KESIMPULAN}

Berdasarkan hasil analisis deskriptif yang dilakukan dapat disimpulkan bahwa karakteristik responden wakif online didominasi oleh donatur berjenenis kelamin perempuan, dengan rentang usia berada pada 19-34 tahun atau termasuk dalam generasi millenials. Sebagian besar responden memiliki latar belakang pendidikan yang baik. Sebesar 60,56 persen berhasil menyelesaikan pendidikan pada perguruan tinggi, dan sebanyak 58,62 persen dari 29 responden yang lulusan SMA sedang menjalani pendidikan di perguruan tinggi. Responden pada penelitian ini didominasi oleh responden dengan berpenghasilan rendah, yaitu penghasilan $<\mathrm{Rp} 2.000 .000$. Hal ini disebabkan karena 28,89 persen dari responden dalam penelitian ini berprofesi sebagai mahasiswa sehingga belum memiliki penghasilan sendiri.

Terkait faktor-faktor yang memengaruhi wakif dalam bewakaf online, hasil analisis faktor menunjukkan bahwa ada lima faktor yang terbentuk, yaitu faktor kualitas informasi, faktor pelayanan, faktor kepercayaan, faktor kualitas website, dan faktor 
promosi. Faktor yang paling memengaruhi wakif dalam berwakaf online adalah kualitas informasi sebesar 15,830 persen dengan variabel informasi program wakaf yang memiliki nilai factor loading tertinggi pada faktor tersebut. Oleh karena itu, bagi lembaga wakaf yang telah atau yang akan menyelenggarakan wakaf online sebaiknya hal utama yang perlu diperhatikan untuk menarik wakif agar berwakaf online adalah mengenai kualitas informasi website dimana setiap lembaga harus menyertakan informasi program wakaf yang ingin dijalani.

\section{REFERENSI}

Antonio MS. 2002. Bank Syariah Sebagai Pengelola Wakaf. Workshop Internasional Pemberdayaan Ekonomi Umat Melalui Wakaf Produktif. 7-8 Januari 2002, Batam, Indonesia.

Bencsik A, Csikos G, Juhaz T. 2016. Y and Z Generations at Workplace. Journal of Competitiveness. Volume 8 (3) : 90-106

Djunaidi A. 2007. Strategi Pengembangan Wakaf Tunai di Indonesia. Jakarta: Direktorat Pemberdayaan Zakat Departemen Agama RI.

Fauzi, M. R. 2009. Pengaruh Personal Selling Terhadap Keputusan Pembelian Konsumen pada CV.3 Libras Multimedia Services Bandung. Tesis. Universitas Kristen Maranatha

Fauziah S. 2018. Faktor-Faktor yang Memengaruhi Persepsi Wakif Terhadap Wakaf Uang di Kota Bogor. Skripsi. Institut Pertanian Bogor

Fauziah U. 2017. Survey Motivasi, Persepsi, Sikap, Religiusitas Wakif Kota Tangerang Selatan. Skripsi. Universitas Islam Negeri Syarif Hidayatullah

Hasanah U. 2009. Telaah - Wakaf Untuk Kesejahteraan Umat. Diakses pada 15 Februari 2019 dari https://m.antaranews.com/berita/142362/telaah--wakaf-untukkesejahteraanumat-oleh-uswatun-hasanah

Kasri, R. A. 2013. Giving Behaviours in Indonesia: motives and marketing implications for Islamic charities. Journal of Islamic Marketing. Volume 4 (3) : 309

Khadijah. 2016. Analisis Faktor-Faktor yang Memengaruhi Penghimpunan Wakaf Uang di Indonesia. Skripsi. Institut Pertanian Bogor

Kuncoro M. 2010. Masalah, Kebijakan, dan Politik Ekonomika Pembangunan. Jakarta: Penerbit Erlangga

Lyons S. 2004. An Exploration of Generational Values in Life and at Work. Tesis. Carleton University

Mauludiyahwati S. 2017. Pengaruh Kepercayaan, Keamanan, Kualitas Pelayanan, dan Persepsi Risiko Menggunakan E-commerce terhadap Keputusan Pembelian Online. Skripsi. Universitas Negeri Yogyakarta

Nasution ME, Hasanah U. 2005. Wakaf Tunai Inovasi Finansial Islam. Peluang dan dalam Mewujudkan Kesejahteraan Umat. Jakarta: PKTII-UI

Nizar A. 2014. Faktor-Faktor yang Memengaruhi Persepsi Wakif Tentang Wakaf Uang. Jurnal Bisnis dan Manajemen. Volume 4 (1): 21-36. 
Pew Research Center. 2014. U.S Religious Landscape. Diakses pada 15 Juni 2019 dari: https://www.pewforum.org/religiouslandscape-study/

Quddus R. 2009. Persepsi Pesantren terhadap Wakaf Uang. Tesis. Universitas Indonesia Rozalinda. 2015. Manajemen Wakaf Produktif. Jakarta: PT RajaGrafindo Persada

Santoso S. 2014. Statistik Multivariat Edisi Revisi. Jakarta: PT. Elex Media Komputindo

Sari, A. C. 2018. Pengaruh Sosialisasi, Religiusitas, dan Pengetahuan terhadap Minat Masyarakat Wonosari untuk Berwakaf Tunai di BMT Dana Insani Gunungkidul. Skripsi. Universitas Islam Negeri Sunan Kalijaga

[SIWAK] Sistem Informasi Wakaf. 2016. Data Penggunaan Tanah Wakaf. Diakses pada 01 Januari 2019 dari https://siwak.kemenag.go.id/index.php

Sudirman, Arofah NL. 2016. Manajemen Wakaf Uang di Masjid at-Taqwa Kota Batu dan Masjid Sabilillah Kota Malang dalam Perspektif Undang-Undang Nomor 41 Tahun 2004 tentang Wakaf. De Jure: Jurnal Hukum dan Syari'ah. Volume 8 (1) : 24-37

Sulaiman S. 2017. Waqf Based Crowdfunding: proposed framework for enterpreneur development. Conference on Philanthropy for Humanitarian Aid (CONPHA). 2324 Mei 2017, Sultan Sharif Ali Islamic University (UNISSA): Brunei Darussalam.

Suliyanto. 2005. Analisis Data dalam Aplikasi Pemasaran. Bogor: Ghalia Indonesia

Supriyadi E. 2014. SPSS + Amos. Bogor: In Media

Syarif A, Wijayanto H. 2017. Analisis Pengaruh Kemenarikan Desain Website, Kepercayaan, dan Profesionalisme terhadap Keputusan Pembelian Online Jasa Aqiqah. Jurnal Ikraith-Informatika: Volume 1(2): 94-103

Tarsi. 2014. Wakaf Uang dengan Sistem Online. Diakses pada 15 Juni 2019 dari https://badilag.mahkamahagung.go.id/artikel/publikasi/artikel/wakafuangdengan-sistem-online-oleh-drshtarsishmhi-182

[UU] Undang-Undang Republik Indonesia Nomor 41 Tahun 2004 Tentang Wakaf

Valanciene L, Jegeleviciute S. 2013. Valuation of Crowdfunding: benefits and drawbacks. Economics and Management. Volume 18 (1) : 39-48

Vulkan N, Astebro T, Sierra MF. 2016. Equity Crowdfunding: a new phenomena. Journal of Business Venturing Insights. Volume 5: 37-49

Widarjono A. 2015. Analisis Multivariat Terapan. Yogyakarta: UPP STIM YKPN

Wijaya, S. W. S, Utami E, Arief, M. R. 2012. Analisis Fitur E-commerce Berdasarkan Conceptual Model of Customer Knowledge Management (CKM). Seminar Nasional Aplikasi Teknologi Informasi (SNATI). 15-16 Juni 2017, Yogyakarta, Indonesia.

Yuniarty, Abbas BS. 2018. Faktor-Faktor Penentu Keputusan Pembelian Melalui Ecommerce pada PT. GRE. Jurnal Manajemen Indonesia. Volume 18 (2): $144-$ 153 